\title{
Utilização de Chama para Controle de Plantas Daninhas Emersas em Ambiente Aquático ${ }^{1}$
}

\author{
Using Flame for Control of Emerged Aquatic Weeds
}

MARCHI, S.R. ${ }^{2}$, VELINI, E.D. ${ }^{3}$, NEGRISOLI, E. ${ }^{2}$ e CORREA, M.R. ${ }^{2}$

\begin{abstract}
RESUMO - Dois estudos foram conduzidos com o objetivo de avaliar os efeitos da aplicação de chama no controle de Eichhornia crassipes, Brachiaria subquadripara, Pistia stratiotes e Salvinia auriculata. No primeiro estudo foram utilizadas diferentes doses de chama, representadas pela quantidade de gás consumida durante a aplicação, e, no segundo, usaram-se duas aplicações de chama em intervalo de 14 dias, uma aplicação seqüencial (intervalo de sete dias) e aplicação única. As diferentes doses, tanto no primeiro quanto no segundo, foram comparadas com plantas que não receberam nenhum tratamento térmico. Avaliações de injúria foram realizadas aos 1, 3, 7, 10, 14, 17, 21 e 30 após a aplicação dos tratamentos, sendo realizadas também avaliações das biomassas secas das plantas aquáticas remanescentes em cada tratamento, ao final dos ensaios. No primeiro estudo foram observadas reduções significativas na produção da biomassa seca das espécies $E$. crassipes, B. subquadripara e $P$. stratiotes tratadas com as maiores doses referentes aos consumos de gás. Doses menores não diferiram estatisticamente da testemunha quanto à produção de biomassa seca, exceção feita para a espécie $P$. stratiotes. Todas as aplicações seqüenciais proporcionaram redução acima de $90 \%$ na produção da biomassa seca de E. crassipes e B. subquadripara. As aplicações seqüenciais e únicas proporcionaram reduções abaixo de $37 \%$ na produção da biomassa seca de S. auriculata. Os resultados demonstraram que existe a possibilidade de se utilizar o controle físico através da aplicação de chama como alternativa no manejo de plantas daninhas em ambientes aquáticos.
\end{abstract}

Palavras-chave: controle físico, chama, planta aquática, aplicação seqüencial.

\begin{abstract}
Two trials were carried out to evaluate the effect of flame weeding on Eichhornia crassipes, Brachiaria subquadripara, Pistia stratiotes and Salvinia auriculata. In the first trial, different doses of flame were applied, according to the amount of gas consumed during application. In the second trial, two flame applications (14 day interval between each application), triple flame application ( 7 day interval between each application) and single flame application were used. Untreated plants were used in both trials as check. Injury was assessed at 1, 3, 7, 10, 13, 17, 21 and 30 days after applications. Dry biomass of survival plants was also obtained at the final experimental period. The first trial results showed a significant reduction in the biomass of E. crassipes, B. subquadripara and P.stratiotes, treated with the highest flame. All the sequential applications provided significant dry biomass reduction (over 90\%) in $\boldsymbol{E}$. crassipes and B. subquadripara. The sequential and single applications provided dry biomass reductions up to $37 \%$ in S. auriculata. The results show that it is viable to use flame weeding as an alternative in the management of aquatic environments.
\end{abstract}

Key words: physical control, flame, aquatic weed, sequential application.

Recebido para publicação em 3.1.2005 e na forma revisada em 11.4.2005.

2 Eng.-Agr., M.S., Doutorando em Agricultura, Dep. de Produção Vegetal/Agricultura, FCA/UNESP, Caixa Postal 237, 18603-970 Botucatu-SP, <srmarchi@fca.unesp.br>; ${ }^{3}$ Prof. Assistente Dr., Dep. de Produção Vegetal/Agricultura, FCA/UNESP, Botucatu-SP. 


\section{INTRODUÇÃO}

O crescente problema de infestação por plantas aquáticas nos diversos corpos hídricos brasileiros e as restrições ao uso de herbicidas em ambientes aquáticos têm motivado os pesquisadores a desenvolver alternativas viáveis e adequadas para seu controle. Os métodos mecânicos de controle têm-se destacado nessa linha de pesquisa, notadamente aqueles relacionados à remoção das plantas através de esteiras picadoras localizadas às margens, colhedoras flutuantes ou retroescavadeiras instaladas em balsas.

Todavia, esses equipamentos de colheita e retirada do material vegetal dos reservatórios geralmente apresentam elevado custo operacional, devido a fatores como custos diretos do maquinário, habilidade dos operadores, custos de propriedade dos equipamentos e custos de terceirização de serviços de transporte do material colhido até uma área de descarte (Antuniassi et al., 2002). Outro fator importante é o baixo rendimento operacional dos equipamentos já desenvolvidos, o que reduz muito o intervalo entre as atividades de manutenção em um mesmo local.

Os métodos físicos que utilizam altas temperaturas, denominados de controles térmicos, poderiam ser uma alternativa de integração de manejo visando complementar o controle mecânico já instalado no referido reservatório.

O emprego de chama para controle de plantas daninhas foi comumente utilizado nos Estados Unidos em culturas anuais como algodão e sorgo entre as décadas de 1930 e 1960. A partir desse período, a técnica de controle térmico de plantas daninhas passou a ser gradativamente abandonada, devido à escalada nos preços dos combustiveis fósseis e ao surgimento dos herbicidas seletivos para as diversas culturas (Seifert \& Snipes, 1998). Entretanto, o controle térmico de plantas daninhas voltou a ganhar expressiva conotação nas décadas de 1980 e 1990, principalmente entre os praticantes da agricultura orgânica dos vários países da Europa, os quais são proibidos de adotar qualquer intervenção química em suas lavouras (Bond \& Grundy, 2001).

Atualmente existem dois tipos fundamentais de equipamentos utilizados no controle térmico de plantas daninhas, a saber: pela emissão de uma chama de aproximadamente $1.900{ }^{\circ} \mathrm{C}$, utilizando um bico difusor, ou pela emissão de uma chama não-visivel de $900{ }^{\circ} \mathrm{C}$, através de difusor infravermelho. Ambos os equipamentos utilizam o gás liquefeito de petróleo (GLP) ou misturas à base de propano/butano como combustivel e possuem como particularidade o fato de não provocarem distúrbios nem deixarem resíduos químicos no solo ou na água da área a ser tratada. Conforme reforçam Hatcher \& Melander (2003), a desvantagem ainda continua sendo o alto custo e consumo de combustiveis fósseis.

O controle térmico de plantas necessariamente exige contato entre a onda de calor gerada pelos difusores e a folha ou planta a ser controlada. A onda de calor deve ter uma temperatura suficiente para causar a ebulição da pequena quantidade de água existente no interior das células. A pressão gerada pela expansão da água irá causar o rompimento das membranas celulares e a rápida desidratação dos tecidos afetados (Ellwanger, 1973).

O método de controle de plantas através da utilização de chamas depende de vários fatores, como temperatura, tempo de exposição e consumo de energia. A desnaturação das células das plantas pode-se iniciar a uma temperatura de cerca de $40{ }^{\circ} \mathrm{C}$, dependendo do tempo de exposição. Contudo, a temperatura necessária para causar morte foliar varia de 55 a $94{ }^{\circ} \mathrm{C}$ (Ascard, 1997), e o tempo de exposição letal suficiente para causar morte de tecidos e plantas daninhas varia de 0,07 a 0,13 seg (Daniell et al., 1969).

Diferentes relações entre a temperatura letal e o tempo de exposição têm sido relatadas, porém todas elas têm em comum o fato de que menores tempos de exposições necessitam de maiores temperaturas e maior consumo de combustivel (Ascard, 1997). Por sua vez, o tempo de exposição no qual o tecido vegetal é exposto ao calor e os consumos de gás resultam diretamente da velocidade de deslocamento do conjunto aplicador. Esse fator foi amplamente discutido por Parish (1990), Ascard (1997) e Rifai et al. (2003), os quais relatam que melhores niveis de controle de plantas daninhas estão associados a velocidades entre 1,0 e $4,0 \mathrm{~km} \mathrm{~h}^{-1}$. 
A eficácia do controle térmico também varia em função da espécie vegetal a ser controlada. A tolerância ou não de uma determinada espécie depende da presença de pêlos ou ceras protetoras, lignificação, condição hídrica da planta e de sua capacidade em rebrotar (Ascard, 1995). No caso de plantas aquáticas, a condição hídrica destas talvez não seja problema; contudo, a presença de pêlos e ceras protetoras talvez possa ser importante em se tratando particularmente das espécies Pistia stratiotes, Salvinia ssp. e Eichhornia crassipes e, no caso de Brachiaria subquadripara, a lignificação possa representar um fator limitante.

Segundo Ascard (1995), as plantas podem ser enquadradas em quatro grupos distintos quanto à sua sensibilidade ao controle físico por chama: plantas muito sensiveis, as quais possuem folhas finas e nenhum tipo de proteção em seus pontos de crescimento; plantas de fácil controle, que possuem algum tipo de proteção em seus pontos de crescimento; plantas tolerantes, que possuem alta capacidade de rebrotarem e só podem ser controladas em suas fases iniciais de desenvolvimento; e plantas muito tolerantes devido ao seu hábito de crescimento rasteiro e postos de crescimento extremamente protegidos, não podendo, conseqüentemente, ser atingidos pelo tratamento térmico. Geralmente, as plantas muito tolerantes não são controladas com apenas uma aplicação de fogo, independentemente de seu estágio de desenvolvimento.

O objetivo deste trabalho foi estudar o efeito da aplicação de chama, em diferentes aplicações e doses, sobre o controle das plantas aquáticas Eichhornia crassipes, Pistia stratiotes, Salvinia auriculata e Brachiaria subquadripara.

\section{MATERIAL E MÉTODOS}

Dois estudos foram conduzidos no Núcleo de Pesquisas Avançadas em Matologia (NUPAM), pertencente ao Departamento de Produção Vegetal - Agricultura da FCA/UNESP, campus de Botucatu, SP, utilizando-se chama para controle de Eichhornia crassipes, Brachiaria subquadripara, Pistia stratiotes e Salvinia auriculata. As plantas aquáticas foram cultivadas em vasos plásticos com capacidade de 2,0 L, mantidos em casa de vegetação sob temperatura constante de $25^{\circ} \mathrm{C}$ e umidade relativa do ar entre 65 e $70 \%$.

Os diferentes tratamentos foram aplicados utilizando-se um equipamento portátil constituído de botijão contendo gás liquefeito de petróleo (GPL), com capacidade de $7,5 \mathrm{~kg}$, munido de um bico difusor de chama. Este equipamento foi acoplado a um pulverizador estacionário automático com ajuste manual de velocidade.

Na Tabela 1 estão apresentados os tratamentos experimentais utilizados no primeiro estudo, os quais consistiram da aplicação de diferentes quantidades de gás obtidas através da variação na velocidade de deslocamento do equipamento difusor de calor, uma vez que este apresentou consumo constante da ordem de $16,69 \mathrm{~kg} \mathrm{~h}^{-1}$. Cabe salientar que a aplicação de gás na dose de $278+278 \mathrm{~kg} \mathrm{ha}^{-1}$ em um intervalo de 5,5 segundos teve a finalidade de simular a utilização de dois difusores acoplados ao mesmo equipamento, o que teoricamente confere maior eficácia ao tratamento térmico.

Os tratamentos do segundo estudo foram estabelecidos após a obtenção dos resultados do primeiro e consistiram da aplicação seqüencial de diferentes quantidades de gás, conforme apresentado na Tabela 2. As aplicações seqüenciais foram realizadas aos 14 dias após a primeira aplicação, com exceção da dose de $278+278+278$, que foi aplicada aos 7 e 14 dias. Em ambos os estudos, os tratamentos foram dispostos no delineamento experimental inteiramente casualizado, com quatro repetições.

Tabela 1 - Velocidades de deslocamento, número de aplicações e consumo de gás $\left(\mathrm{kg} \mathrm{ha}^{-1}\right)$ utilizados no primeiro estudo. Botucatu, SP, 2004

\begin{tabular}{|c|c|c|c|}
\hline Tratamento & $\begin{array}{c}\text { Velocidade } \\
\left(\mathrm{km} \mathrm{h}^{-1}\right)\end{array}$ & $\begin{array}{c}\text { Número de } \\
\text { aplicações }\end{array}$ & $\begin{array}{c}\text { Consumo de gás } \\
\left(\mathrm{kg} \mathrm{ha}^{-1}\right)\end{array}$ \\
\hline 1 & 0,5 & 1 & 2.226 \\
\hline 2 & 1,0 & 1 & 1.113 \\
\hline 3 & 2,0 & 1 & 556 \\
\hline 4 & 3,0 & 1 & 371 \\
\hline 5 & 4,0 & 1 & 278 \\
\hline 6 & 4,0 & $2^{\frac{1}{}}$ & $278+278$ \\
\hline 7 & - & - & 0 \\
\hline
\end{tabular}

1/ Correspondente a duas aplicações de $4,0 \mathrm{~km} \mathrm{~h}^{-1}$, com intervalo médio entre aplicações de 5,5 segundos.

Planta Daninha, Viçosa-MG, v. 23, n. 2, p. 311-319, 2005 
Tabela 2 - Velocidades de deslocamento, número de aplicações, intervalo entre aplicações e consumo de gás $\left(\mathrm{kg} \mathrm{ha}^{-1}\right)$ utilizados no segundo estudo. Botucatu, SP, 2004

\begin{tabular}{|c|c|c|c|c|}
\hline Tratamento & $\begin{array}{c}\text { Velocidade } \\
\left(\mathrm{km} \mathrm{h}^{-1}\right)\end{array}$ & $\begin{array}{c}\text { Consumo e gás } \\
\left(\mathrm{kg} \mathrm{ha}^{-1}\right)\end{array}$ & $\begin{array}{c}\text { Número de } \\
\text { aplicações }\end{array}$ & $\begin{array}{c}\text { Intervalo entre } \\
\text { aplicações } \\
(\text { dias })\end{array}$ \\
\hline 1 & 1,0 & 1.113 & 1 & 0 \\
\hline 2 & $1,0+2,0$ & $1.113+556$ & 2 & $0+14$ \\
\hline 3 & $1,0+3,0$ & $1.113+371$ & 2 & $0+14$ \\
\hline 4 & 2,0 & 556 & 1 & 0 \\
\hline 5 & $2,0+2,0$ & $556+556$ & 2 & $0+14$ \\
\hline 6 & $2,0+3,0$ & $556+371$ & 2 & $0+14$ \\
\hline 7 & $4,0+4,0+4,0$ & $278+278+278$ & 3 & $0+7+14$ \\
\hline 8 & - & 0 & 0 & - \\
\hline
\end{tabular}

Os vasos com as plantas aquáticas foram posicionadas $30 \mathrm{~cm}$ abaixo do bico difusor de chama, distância esta capaz de produzir uma faixa de controle de $15 \mathrm{~cm}$ de largura. A largura da faixa foi obtida pela leitura direta da marca feita em cartolina após a aplicação da chama sobre esta.

Os efeitos dos tratamentos foram avaliados aos 1, 3, 7, 10, 14, 17, 21 e 30 depois da aplicação dos tratamentos. Nestas datas foram avaliadas a mortalidade de plantas e a injúria proporcionada pelos tratamentos, de acordo com a escala na qual zero representou ausência de injúria e $100 \%$ a morte total da planta. Ao final dos ensaios foram avaliadas as biomassas secas das plantas aquáticas remanescentes em cada tratamento. Os resultados de biomassa seca foram submetidos à análise de variância pelo teste $\mathrm{F}$, e a comparação das médias dos tratamentos foi feita pelo teste $\mathrm{t}$ a $5 \%$ de probabilidade.

\section{RESULTADOS E DISCUSSÃO}

Na Figura 1 estão apresentadas as evoluções de injúria proporcionadas pela aplicação de chama, em diferentes doses, sobre as plantas de E. crassipes no primeiro estudo. Pode-se notar que todas as doses testadas proporcionaram injúrias já no primeiro dia após a aplicação (DAA) da chama, sendo as maiores doses responsáveis também pelos maiores valores de injúria. Todas as doses também apresentaram rápida evolução de injúria aos 3 DAA, data na qual alcançaram seus valores máximos. Os melhores resultados de injúria foram proporcionados pelas doses de 2.226,
$1.113,556$ e $371 \mathrm{~kg} \mathrm{ha}^{-1}$, os quais alcançaram valores superiores a $80 \%$ já aos 3 DAA. O tratamento representado pela aplicação seqüencial de $278+278 \mathrm{~kg} \mathrm{ha}^{-1}$ proporcionou resultados intermediários da ordem de $70 \%$, e a aplicação única de $278 \mathrm{~kg} \mathrm{ha}^{-1}$ foi a que apresentou os menores valores de injúria (abaixo de 45\%).

Esses resultados de injúria permaneceram praticamente constantes até a avaliação realizada aos 14 DAA, data a partir da qual foi possivel se observar rápida recuperação das plantas através do surgimento de novas folhas em seus pontos terminais de crescimento. Não foi observada morte de plantas de E. crassipes em nenhuma das doses testadas, e a injúria tendeu a zero aos 30 DAA.

Na Figura 2, pode-se notar que as doses de chama testadas em $B$. subquadripara proporcionaram resultados semelhantes àqueles verificados em E. crassipes, ou seja, injúrias visíveis já a $1 \mathrm{DAA}$, com tendência de elevação aos 3 DAA e estabilização até os 14 DAA. Os maiores valores de injúria foram proporcionados pelas doses de 2.226, 1.113, 556 e $371 \mathrm{~kg} \mathrm{ha}^{-1}$, atingindo valores superiores a $90 \%$ aos 3 DAA. Nesta mesma data de avaliação, as doses de 278 e $278+278 \mathrm{~kg} \mathrm{ha}^{-1}$ produziram injúrias intermediárias de $51 \mathrm{e}$ $63 \%$, respectivamente. A recuperação das plantas se iniciou aos 14 DAA, tendendo a zero aos 30 DAA. Nenhuma das doses testadas proporcionou morte total de plantas de B. subquadripara.

Apenas as doses de 2.226, 1.113 e $556 \mathrm{~kg} \mathrm{ha}^{-1}$ proporcionaram injúrias superiores a $80 \%$ em $P$. stratiotes aos 3 DAA (Figura 3). As doses de 371 e $278+278 \mathrm{~kg} \mathrm{ha}^{-1}$ proporcionaram injúrias de 48 e $33 \%$, respectivamente. O pior desempenho foi observado quando da aplicação da dose única de gás a $278 \mathrm{~kg} \mathrm{ha}^{-1}$, com injúrias inferiores a $5 \%$ ao longo de todo o período de avaliação. Os valores de injúria também começaram a regredir a partir dos 14 DAA, havendo total recuperação das plantas aos 30 DAA. Essa total recuperação das plantas revela que as doses não foram suficientes para causar morte desta espécie de plantas.

Na Figura 4 também estão apresentadas as evoluções das injúrias causadas pelas 
doses de gás utilizadas em $S$. auriculata. Os níveis de injúria sempre estiveram abaixo dos $60 \%$, independentemente da época de avaliação e da dose de gás. Embora os niveis de injúria tenham sido baixos, a recuperação das plantas também se iniciou somente aos 14 DAA, chegando a zero aos 30 DAA.

A eficácia do controle térmico e a sobrevivência da planta após o tratamento térmico podem ser devida à falta de contato do calor proveniente da chama com a planta ou à tolerância da planta ao calor. O contato entre o calor e a planta depende da técnica de emissão de calor utilizada, da estrutura da planta e da presença de umidade na superficie das diversas estruturas da planta (Leroux et al., 2001). Já a tolerância se deve à presença de camadas protetoras, como pêlos e ceras, lignificação, teor de água e capacidade de rebrota nas plantas (Laguë et al., 2001).

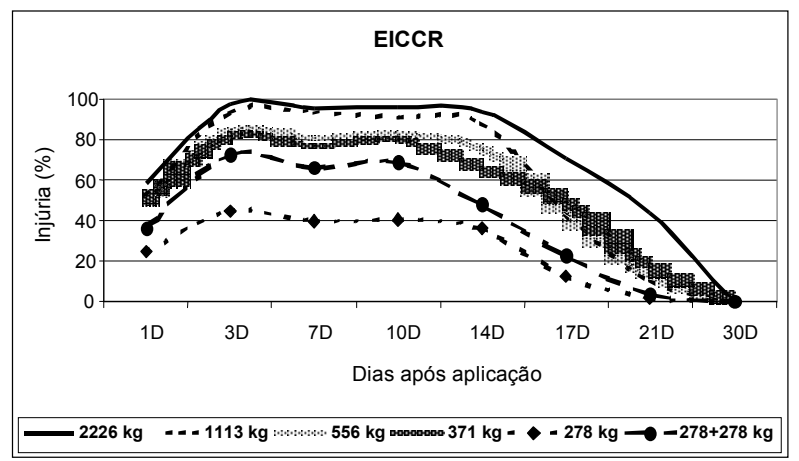

Figura 1 - Evoluções de injúria proporcionadas pela aplicação de chama, em diferentes doses, sobre Eichhornia crassipes. Botucatu, SP, 2004.

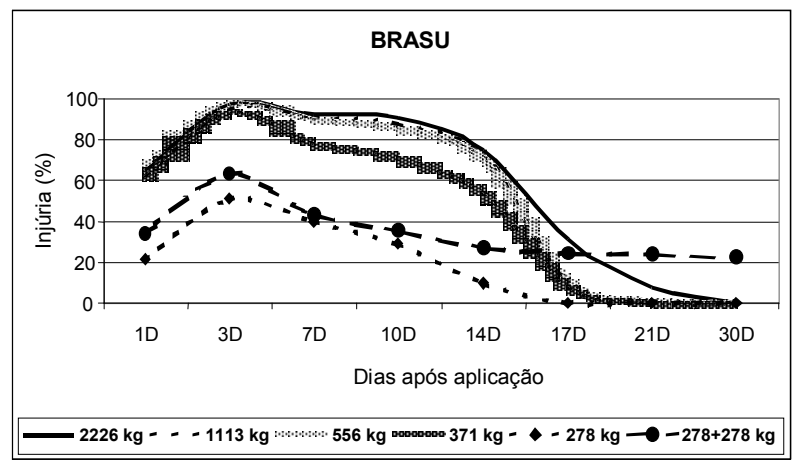

Figura 2 - Evoluções de injúria proporcionadas pela aplicação de chama, em diferentes doses, sobre Brachiaria subquadripara. Botucatu, SP, 2004.
As plantas aquáticas E. crassipes, $B$. subquadripara e $P$. stratiotes podem ser classificadas como tolerantes ao controle térmico por chama, conforme classificação descrita por Ascard (1995), uma vez que os tratamentos não foram eficientes no controle dessas espécies, mesmo proporcionando niveis elevados de injúria. As três espécies rebrotaram, em virtude de seus respectivos pontos de crescimento estarem localizados próximos ou abaixo da superficie da água, o que confere a proteção (Figura 5).

A espécie $S$. auriculata pode ser considerada muito tolerante, pois não foi afetada pela aplicação da chama e rebrotou aos 14 DAA. Esta espécie, além de possuir seu ponto de crescimento protegido, também apresenta hábito de crescimento na superficie da água. O constante contato das folhas de salvinia com a água, provavelmente, não permite que a

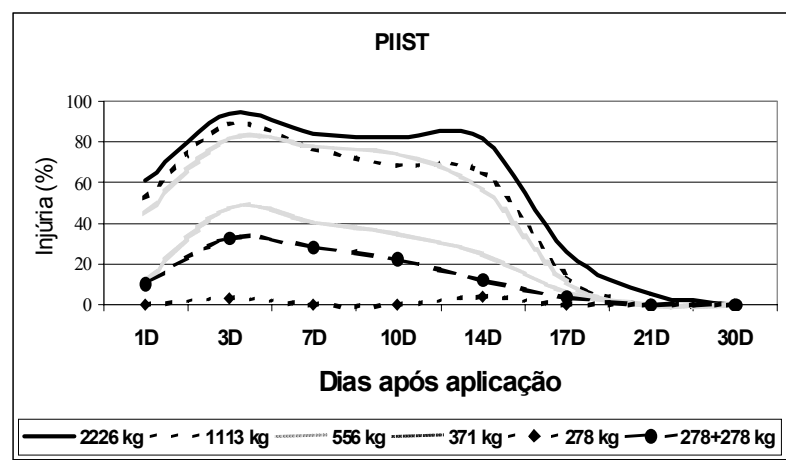

Figura 3 - Evoluções de injúria proporcionadas pela aplicação de chama, em diferentes doses, sobre Pistia stratiotes. Botucatu, SP, 2004.

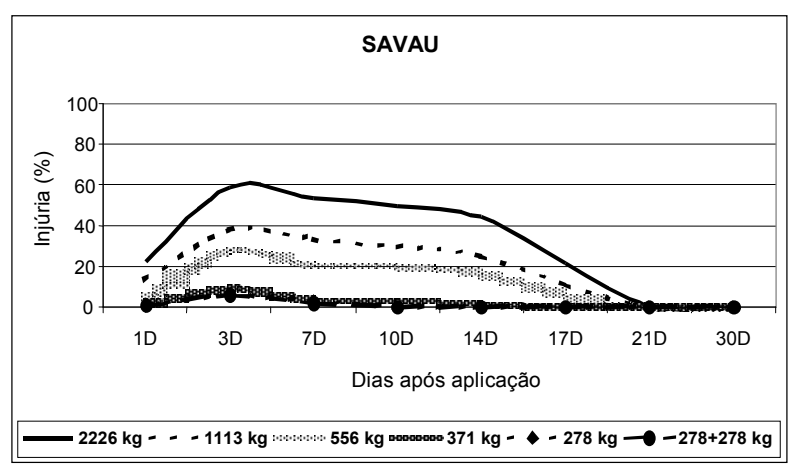

Figura 4 - Evoluções de injúria proporcionadas pela aplicação de chama, em diferentes doses, sobre Salvinia auriculata. Botucatu, SP, 2004.

Planta Daninha, Viçosa-MG, v. 23, n. 2, p. 311-319, 2005 
temperatura no interior das células se eleve a ponto de promover o rompimento das paredes celulares, o que explica os baixos niveis de injúria deste trabalho. Seifert \& Snipes (1996, 1998) observaram efeitos mínimos de injúria na cultura do algodão quando uma lâmina de água foi pulverizada nas plantas imediatamente antes da aplicação do tratamento térmico da chama. Os autores ainda comentam que o desenvolvimento da planta e a produtividade não foram afetados pelo tratamento térmico.

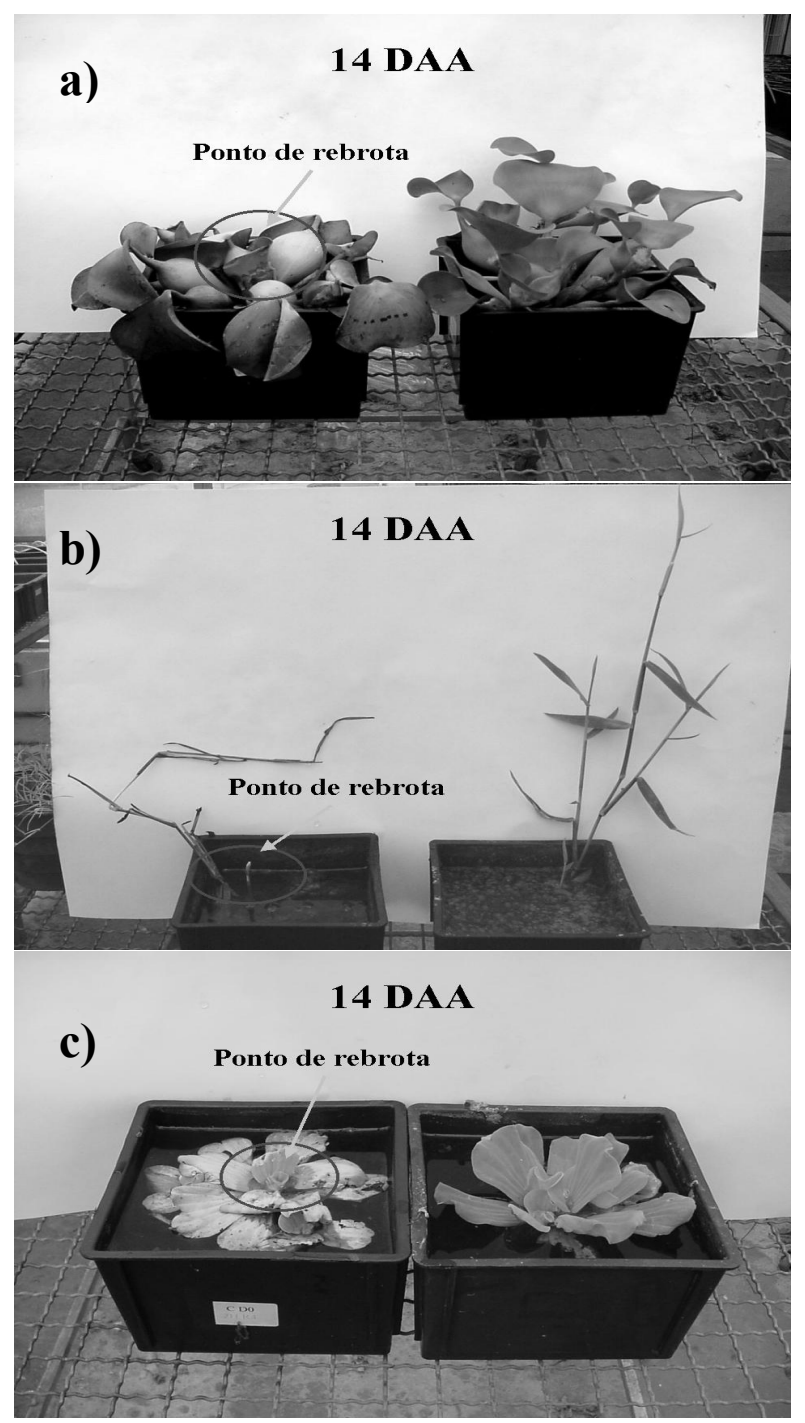

Figura 5 - Detalhe da rebrota do ponto de crescimento de $E$. crassipes (a), B. subquadripara (b) e P. stratiotes (c) que esteve protegido pela água durante a aplicação da chama. Botucatu, SP, 2004.
Embora não tenha ocorrido morte das plantas tratadas, na Tabela 3 é possivel notar que ocorreram reduções significativas na produção da biomassa seca em função dos diferentes consumos de gás utilizados nos tratamentos térmicos. A produção de biomassa seca das espécies E. crassipes, B. subquadripara, $P$. stratiotes e $S$. auriculata tratadas com as doses referentes ao consumo de gás de 2.226, $1.113,556$ e $371 \mathrm{~kg} \mathrm{ha}^{-1}$ foi estatisticamente inferior à produção de biomassa seca da testemunha aos 30 DAA. As doses de 278 e $278+278 \mathrm{~kg} \mathrm{ha}^{-1}$ não diferiram estatisticamente da testemunha quanto à produção de biomassa seca, exceção feita para as espécies $S$. auriculata e $P$. stratiotes, respectivamente.

De maneira geral, as maiores doses de gás produziram maiores valores de redução percentual de biomassa seca aos 30 DAA, quando comparados com os da testemunha (Tabela 3). As maiores reduções percentuais de biomassa seca foram observadas em B. subquadripara, com que as doses de 2.226, 1.113 e $556 \mathrm{~kg} \mathrm{ha}^{-1}$ proporcionando reduções de $77,6,74,2$ e $78,3 \%$, respectivamente. A dose de $371 \mathrm{~kg} \mathrm{ha}^{-1}$ também proporcionou um bom indice de redução percentual de biomassa seca: aproximadamente $59 \%$, aos 30 DAA. Contrariamente, os menores percentuais de redução de biomassa seca foram observados em S. auriculata, comprovando sua alta tolerância ao controle físico por meio de fogo.

Rahkonen \& Vanhala (1993) estudaram a resposta de uma comunidade de plantas composta por Chenopodium album, Matricaria inodora e Phleum pratense a diferentes doses de tratamento térmico e verificaram que $M$. inodora apresentou menores niveis de injúrias quando comparada com as outras duas espécies, o que possibilitou uma maior vigor de rebrota e rápida ocupação dos espaços deixados pelas espécies mais sensiveis. Com vantagem competitiva, $M$. inodora produziu maior quantidade de biomassa seca, quando comparada com uma área que não recebeu tratamento térmico.

Ascard (1995) comparou a resposta de diferentes plantas daninhas tratadas com várias doses de tratamento térmico e verificou que Sinapsis media, C. album e Urtica urens apresentaram-se relativamente sensiveis ao 
Tabela 3 - Biomassas secas produzidas pelas espécies aquáticas emersas, durante o primeiro estudo, em função dos diferentes consumos de gás nos tratamentos térmicos. Botucatu, SP, 2004

\begin{tabular}{|c|c|c|c|c|c|}
\hline \multirow{2}{*}{$\begin{array}{l}\text { Consumo de gás } \\
\left(\mathrm{kg} \mathrm{ha}^{-1}\right)\end{array}$} & \multirow{2}{*}{$\begin{array}{l}\text { Número de } \\
\text { aplicações }\end{array}$} & \multicolumn{4}{|c|}{ Biomassa seca (g) } \\
\hline & & EICCR & BRASU & PIIST & SAVAU \\
\hline 2.226 & 1 & $\begin{array}{c}6,75 \mathrm{dc} \\
(40,4 \%)^{-2}\end{array}$ & $\begin{array}{c}0,78 \mathrm{~b} \\
(77,6 \%)\end{array}$ & $\begin{array}{c}1,33 \mathrm{~b} \\
(46,7 \%)\end{array}$ & $\begin{array}{c}2,07 \mathrm{~d} \\
(42,4 \%)\end{array}$ \\
\hline 1.113 & 1 & $\begin{array}{c}5,97 \mathrm{dc} \\
(47,3 \%)\end{array}$ & $\begin{array}{c}0,90 \mathrm{~b} \\
(74,3 \%)\end{array}$ & $\begin{array}{c}1,92 \mathrm{ab} \\
(22,6 \%)\end{array}$ & $\begin{array}{c}2,41 \mathrm{~cd} \\
(33,1 \%)\end{array}$ \\
\hline 556 & 1 & $\begin{array}{l}7,89 \mathrm{bdc} \\
(30,3 \%)\end{array}$ & $\begin{array}{c}0,76 \mathrm{~b} \\
(78,3 \%)\end{array}$ & $\begin{array}{c}1,57 \mathrm{~b} \\
(46,7 \%)\end{array}$ & $\begin{array}{c}2,35 \mathrm{~cd} \\
(36,7 \%)\end{array}$ \\
\hline 371 & 1 & $\begin{array}{c}4,70 \mathrm{~d} \\
(58,5 \%)\end{array}$ & $\begin{array}{c}1,42 \mathrm{~b} \\
(59,4 \%)\end{array}$ & $\begin{array}{c}1,68 \mathrm{~b} \\
(32,3 \%)\end{array}$ & $\begin{array}{l}2,60 \mathrm{bcd} \\
(27,7 \%)\end{array}$ \\
\hline 278 & 1 & $\begin{array}{l}10,67 \mathrm{ab} \\
(5,78 \%)\end{array}$ & $\begin{array}{c}3,00 \mathrm{a} \\
(14,2 \%)\end{array}$ & $\begin{array}{l}1,89 \mathrm{ab} \\
(23,8 \%)\end{array}$ & $\begin{array}{l}2,81 \mathrm{cb} \\
(21,8 \%)\end{array}$ \\
\hline $278+278$ & $2^{-1 /}$ & $\begin{array}{l}8,75 \mathrm{abc} \\
(22,7 \%)\end{array}$ & $\begin{array}{c}2,72 \mathrm{a} \\
(22,2 \%)\end{array}$ & $\begin{array}{c}1,27 \mathrm{~b} \\
(48,9 \%)\end{array}$ & $\begin{array}{c}3,05 \mathrm{ab} \\
(15,2 \%)\end{array}$ \\
\hline 0 & - & $\begin{array}{c}11,33 a \\
(-)\end{array}$ & $\begin{array}{c}3,50 \mathrm{a} \\
(-)\end{array}$ & $\begin{array}{c}2,49 a \\
(-)\end{array}$ & $\begin{array}{c}3,60 \mathrm{a} \\
(-)\end{array}$ \\
\hline F Trat. & & $0,0042 * *$ & $0,0002 * *$ & $0,0252 * *$ & $0,0004 * *$ \\
\hline CV $(\%)$ & & 28,45 & 45,29 & 27,26 & 14,50 \\
\hline d.m.s. & & 3,3508 & 1,2447 & 0,6958 & 0,5752 \\
\hline
\end{tabular}

** significativo a $1 \%$ de probabilidade. Médias seguidas de mesma letra na coluna não diferem estatisticamente entre si pelo teste $t(p>0,05)$.

1/ Correspondente a duas aplicações de $4,0 \mathrm{~km} \mathrm{~h}^{-1}$, com intervalo médio entre aplicações de 5,5 segundos. ํ/ Porcentagem de redução de biomassa seca em relação à testemunha.

controle térmico, enquanto Chenopodium bursa-pastoris e Chamomilla suaveolens mostraram sensibilidade intermediária e rápida rebrota após o tratamento. A espécie Poa annua foi muito afetada pelo tratamento térmico, porém também rebrotou rapidamente, pelo fato de seus pontos de crescimento basal estarem protegidos contra a ação do calor.

Semelhantemente, a adoção do controle térmico através da aplicação única de chama em uma população mista composta por E. crassipes, B. subquadripara, P. stratiotes e $S$. auriculata provavelmente poderá ocasionar aumento na produção da biomassa de $S$. auriculata em detrimento das demais espécies, uma vez que esta apresentou maior tolerância ao calor.

No segundo estudo, a aplicação seqüencial de chama foi feita exatamente aos 14 dias após a primeira aplicação, época na qual foi verificada maior recuperação das plantas a partir das injúrias proporcionadas pela aplicação única das diferentes doses de gás no primeiro estudo.
Na Tabela 4, é possivel notar que as aplicações seqüenciais de chama nas diferentes doses de gás foram significativamente superiores às aplicações únicas no controle de $E$. crassipes e $B$. subquadripara, inclusive aquelas em que foram utilizadas doses menores. Via de regra, as reduções na biomassa seca de E. crassipes e B. subquadripara proporcionadas pelas aplicações seqüenciais foram superiores a $90 \%$, chegando próximo a $100 \%$ nas doses de $1.113+556$ e $556+556 \mathrm{~kg} \mathrm{ha}^{-1}$. As aplicações seqüenciais também proporcionaram reduções significativas na produção de biomassa seca de $P$. stratiotes, embora estas tenham diferenciado estatisticamente somente da menor dose: $556 \mathrm{~kg} \mathrm{ha}^{-1}$. A aplicação seqüencial de chama nas doses de $1.113+556$, $1.113+371$ e $556+556 \mathrm{~kg} \mathrm{ha}^{-1}$ proporcionou índices de redução na produção de biomassa seca de 79,0, 80,7 e 73,5\%, respectivamente.

Ascard (1995) comenta que as plantas tratadas com dose única de chama ficam expostas por um curto período ao calor e, por isso, somente os tecidos mais expostos podem

Planta Daninha, Viçosa-MG, v. 23, n. 2, p. 311-319, 2005 
Tabela 4 - Biomassas secas produzidas pelas espécies aquáticas emersas, durante o segundo estudo, em função das aplicações seqüenciais das diferentes quantidades de gás nos tratamentos térmicos. Botucatu, SP, 2004

\begin{tabular}{|c|c|c|c|c|c|}
\hline \multirow{2}{*}{$\begin{array}{c}\text { Consumo de gás (kg } \\
\left.\mathrm{ha}^{-1}\right)\end{array}$} & \multirow{2}{*}{$\begin{array}{c}\text { Intervalo entre } \\
\text { aplicações (dias) }\end{array}$} & \multicolumn{4}{|c|}{ Biomassa seca $(\mathrm{g})$} \\
\hline & & EICCR & BRASU & PIIST & SAVAU \\
\hline 1.113 & 0 & $\begin{array}{c}2,44 \mathrm{c} \\
(53,2 \%)^{-1}\end{array}$ & $\begin{array}{c}0,82 \mathrm{c} \\
(84,9 \%)\end{array}$ & $\begin{array}{c}1,60 \mathrm{a} \\
(61,8 \%)\end{array}$ & $\begin{array}{c}1,41 \mathrm{ab} \\
(30,5 \%)\end{array}$ \\
\hline $1.113+556$ & $0+14$ & $\begin{array}{c}0,14 \mathrm{ab} \\
(97,3 \%)\end{array}$ & $\begin{array}{c}0,11 \mathrm{a} \\
(98,0 \%)\end{array}$ & $\begin{array}{c}0,88 \mathrm{a} \\
(79,0 \%)\end{array}$ & $\begin{array}{c}1,42 \mathrm{ab} \\
(30,0 \%)\end{array}$ \\
\hline $1.113+371$ & $0+14$ & $\begin{array}{c}1,21 \mathrm{~b} \\
(76,8 \%)\end{array}$ & $\begin{array}{c}0,12 \mathrm{a} \\
(97,8 \%)\end{array}$ & $\begin{array}{c}0,81 \mathrm{a} \\
(80,7 \%)\end{array}$ & $\begin{array}{c}1,38 \mathrm{a} \\
(32,0 \%)\end{array}$ \\
\hline 556 & 0 & $\begin{array}{c}4,62 d \\
(11,3 \%)\end{array}$ & $\begin{array}{c}1,01 \mathrm{c} \\
(81,5 \%)\end{array}$ & $\begin{array}{c}2,82 \mathrm{~b} \\
(32,7 \%)\end{array}$ & $\begin{array}{l}1,76 \mathrm{bcd} \\
(13,3 \%)\end{array}$ \\
\hline $556+556$ & $0+14$ & $\begin{array}{c}0,00 \mathrm{a} \\
(100 \%)\end{array}$ & $\begin{array}{c}0,14 \mathrm{a} \\
(97,4 \%)\end{array}$ & $\begin{array}{c}1,11 \mathrm{a} \\
(73,5 \%)\end{array}$ & $\begin{array}{c}1,29 a \\
(36,4 \%)\end{array}$ \\
\hline $556+371$ & $0+14$ & $\begin{array}{c}0,07 \mathrm{ab} \\
(98,7 \%)\end{array}$ & $\begin{array}{c}0,47 \mathrm{ba} \\
(91,4 \%)\end{array}$ & $\begin{array}{c}1,59 \mathrm{a} \\
(62,1 \%)\end{array}$ & $\begin{array}{l}1,49 \mathrm{abc} \\
(26,6 \%)\end{array}$ \\
\hline $278+278+278$ & $0+7+14$ & $\begin{array}{c}0,87 \mathrm{ab} \\
(93,3 \%)\end{array}$ & $\begin{array}{c}0,42 b \\
(92,3 \%)\end{array}$ & $\begin{array}{c}1,24 \mathrm{a} \\
(70,4 \%)\end{array}$ & $\begin{array}{l}1,85 \mathrm{~cd} \\
(8,9 \%)\end{array}$ \\
\hline 0 & - & $\begin{array}{c}5,21 \mathrm{~d} \\
(-)\end{array}$ & $\begin{array}{c}5,45 \mathrm{~d} \\
(-)\end{array}$ & $\begin{array}{c}4,19 \mathrm{c} \\
(-)\end{array}$ & $\begin{array}{c}2,03 \mathrm{~d} \\
(-)\end{array}$ \\
\hline F Trat. & & $25,49 * *$ & $429,49 * *$ & $13,74 * *$ & $4,70 * *$ \\
\hline $\mathrm{CV}(\%)$ & & 45,20 & 16,29 & 35,23 & 15,45 \\
\hline d.m.s. & & 1,1993 & 0,2539 & 0,9157 & 0,3559 \\
\hline
\end{tabular}

** significativo a $1 \%$ de probabilidade. Médias seguidas de mesma letra na coluna não diferem estatisticamente entre si pelo teste $\mathrm{t}(\mathrm{p}>0,05)$.

1/ Porcentagem de redução de biomassa seca em relação à testemunha.

ser inicialmente rompidos. Uma segunda aplicação de chama espaçada de uma semana pode alcançar os tecidos mais protegidos e, conseqüentemente, proporcionar maior eficácia de controle, quando comparada com a aplicação única. Esse autor sugere ainda que a segunda aplicação da chama pode ser feita logo que a planta comece a rebrotar, com o objetivo de exaurir totalmente suas reservas bioquimicas.

Na Tabela 4 também é possivel notar que tanto as aplicações únicas quanto as seqüenciais de chama não foram eficientes para reduzir a produção de biomassa seca de S. auriculata, uma vez que as porcentagens de redução foram inferiores a 36\%. Esses resultados reforçam ainda mais a tolerância desta espécie ao tratamento térmico.

Mesmo não proporcionando controle efetivo das plantas estudadas, o controle físico através da emissão de chamas pode representar uma alternativa viável no processo de manejo integrado de plantas daninhas em ambientes aquáticos, pois possibilita reduções significativas na produção de biomassa seca por um período de até 30 dias após a aplicação.

\section{LITERATURA CITADA}

ANTUNIASSI, U. R.; VELINI, E. D.; MARTINS, D. Remoção mecânica de plantas aquáticas: análise econômica e operacional. Planta Daninha, v. 20, p. 35-43, 2002. (Edição especial)

ASCARD, J. Effects of flame weeding on weed species at different developmental stages. Weed Res., v. 35, p. $397-$ 411, 1995.

ASCARD, J. Flame weeding: effects of fuel pressure and tandem burners. Weed Res., v. 37, p. 77-86, 1997.

BOND, W.; GRUNDY, A. C. Non-chemical weed management in organic farming systems. Weed Res., v. 41, p. 383-405, 2001.

DANIELL, J. W.; CHAPELL, W. E.; COUCH, H. B. Effect of sub-lethal and lethal temperatures on plant cells. Plant Physiol., v. 44, p. 1684-1689, 1969.

ELLWANGER, T. C. Physiological effects of ultra-high temperatures on corn. Weed Sci., v. 21, p. 296-299, 1973. 
HATCHER, P. E.; MELANDER, B. Combining physical, cultural and biological methods: prospects for integrated non-chemical weed management strategies. Weed Res., v. 43, p. 303-322, 2003.

LAGUË, C.; GILL, J.; PÉLOQUIN, G. Thermal control in plant protection. In: VINCENT, C.; PANNETON, B.; FLEURAT-LASSARD, F. (Eds.). Physical control methods in plant protection. Berlin: Springer-Verlag, 2001. p. $35-46$.

LEROUX, G. D.; DOUHÉRET, J.; LANOUETTE, M. Flame weeding in corn. In: VINCENT, C.; PANNETON, B.; FLEURAT-LASSARD, F. (Eds.) Physical control methods in plant protection. Berlin: Springer-Verlag, 2001. p. 47-60.

PARISH, S. A review of non-chemical weed control techniques. Biol. Agric. Hortic., v. 7, p. 117-137, 1990.
RAHKONEN, J.; VANHALA, P. Response of a mixed stand to flame and use of temperature measurements predicting weed control efficiency. In: INTERNATIONAL CONFERENCE I.F.O.A.M. NON-CHEMICAL WEED CONTROL, 4., 1993, Dijon. Proceedings... Dijon: 1993. p. $177-181$.

RIFAI, M. N. et al. Comparison of infrared, flame and steam units for their use in plant protection. Res. Agron. Eng., v. 49, n. 2, p. 65-73, 2003.

SEIFERT, S.; SNIPES, C. E. Influence of flame cultivation on mortality of cotton (Gossypium hirsutum) pests and beneficial insects. Weed Technol., v. 10, n. 3, p. 544-549, 1996.

SEIFERT, S.; SNIPES, C. E. Response of cotton (Gossypium hirsutum) to flame cultivation. Weed Technol., v. 12 , n. 3 , p. $470-473,1998$. 